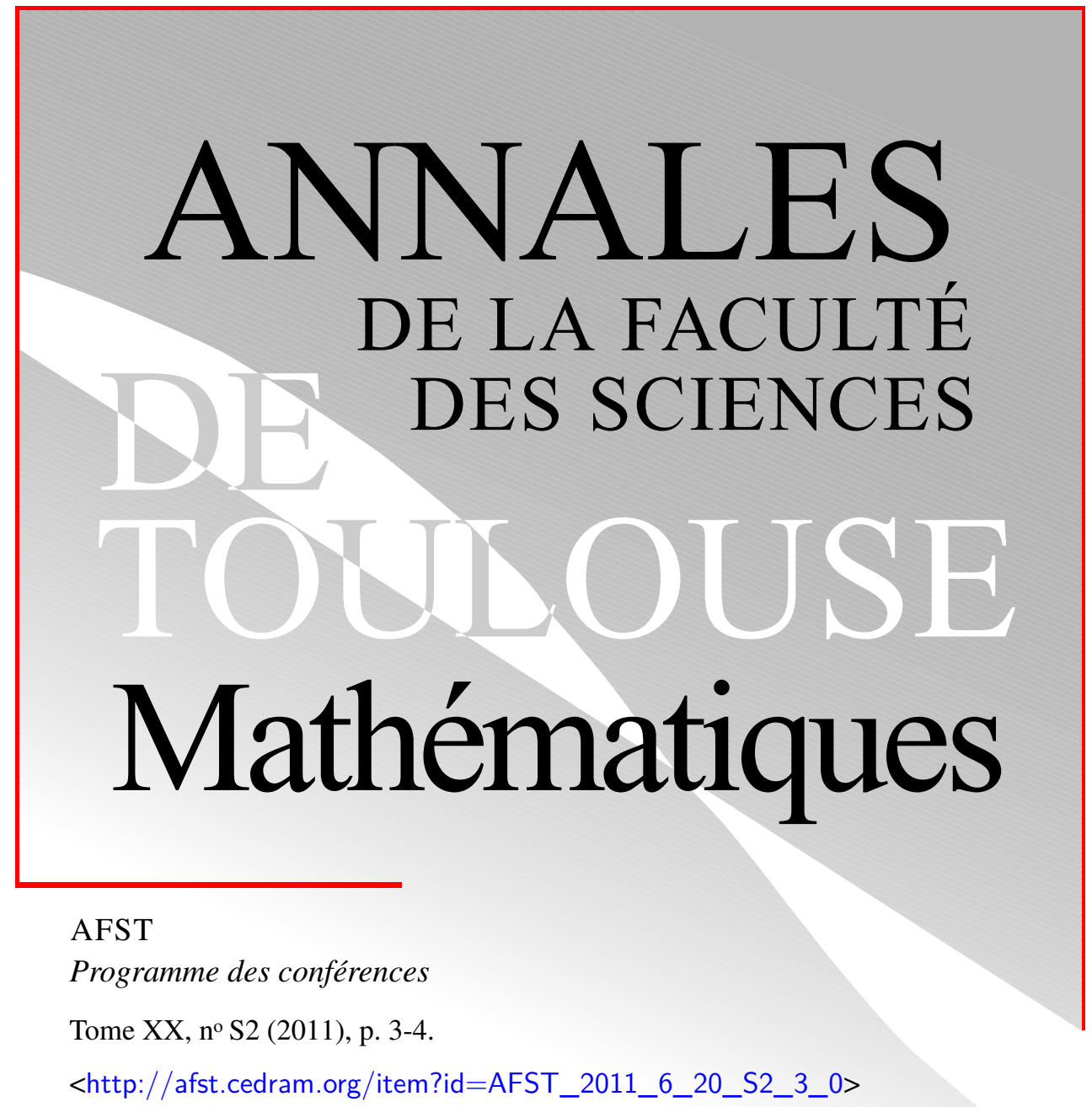

C Université Paul Sabatier, Toulouse, 2011, tous droits réservés.

L'accès aux articles de la revue «Annales de la faculté des sciences de Toulouse Mathématiques » (http://afst.cedram.org/), implique l'accord avec les conditions générales d'utilisation (http://afst.cedram. org/legal/). Toute reproduction en tout ou partie cet article sous quelque forme que ce soit pour tout usage autre que l'utilisation à fin strictement personnelle du copiste est constitutive d'une infraction pénale. Toute copie ou impression de ce fichier doit contenir la présente mention de copyright.

\title{
cedram
}

Article mis en ligne dans le cadre du

Centre de diffusion des revues académiques de mathématiques

http://www.cedram.org/ 


\section{Programme des conférences}

\section{Jeudi 16 octobre}

$10 \mathrm{~h}-10 \mathrm{~h} 50$ Bo Berdntsson : Bergman kernels and Fekete points (after Berman, Boucksom and Witt).

11 h 20 - 12 h 10 Wiesław Plesniak : Recent Progress in the Study of Pluriregularity. (annulé)

12 h 20 - 12 h 50 Mme Burglind JÖRICKE : Pluripolar hulls and fine analytic continuation.

14 h 30 - 15 h 20 Azimbay SAdullaev : Plurisubharmonic continuation in a fixed direction.

15 h $30-16$ h 00 Friedrich HASLINGER : Aspects of compactness for the $\bar{\partial}$-Neumann problem.

16 h 10 - 17 h Vyacheslav ZAKHARYUTA : Kolmogorov problem on widths asymptotics.

17 h 10 - 18 h 00 Lukas Kosinski : Classification of proper holomorphic maps between non-hyperbolic Reinhardt domains.

\section{Vendredi 17 octobre}

9 h $00-9$ h 50 J-P. Demailly : Universal canonical metrics on pseudoeffective Kawamata log terminal pairs $(X ; D)$.

10 h $00-10 \mathrm{~h} 30$ Vincent GuEDJ : Finite energy classes and complex MongeAmpère equations.

11 h 00 - 11 h 50 Urban Cegrell : The Monge-Ampère equation.

12 h $00-12$ h 50 Stawomir KoŁOzIEJ : Volume of sublevel sets of plurisubharmonic functions and the theorem of Demailly.

14h 30 - 15 h 20 Thomas Bloom : Random matrices and potential theory. 15 h 30 - 16 h 00 Taib Belghiti : Approximation polynomiale sur des compacts vérifiant la condition SL. (annulé) 
16 h 30 - 17 h 20 Tien Cuong Dinh : Exponential estimates for MongeAmpère measures and complex dynamics.

\section{Samedi 18 octobre}

9 h $00-9$ h 50 B. Al TAYLOR : High order tangents to analytic varieties and Phragmen-Lindelöf conditions.

10 h $00-10$ h 30 R. Sigurdsson : Disc envelope formulas for the SiciakZahariuta extremal functions and characterization of polynomial hulls.

11 h 00 - 11 h 50 Julien Duval : Sur le deuxième théorème de Nevanlinna.

12 h $00-12$ h 50 Ha Huy KHOAI : Nevalinna Theory, unique range sets and decomposition of meromorphic functions.

14 h $30-15$ h 20 Jozef SiCIAK : Sets in $\mathbb{C}^{n}$ with vanishing extremal function. 15 h $30-16$ h 00 Christophe Dupont : On the dimension of the equilibrium measure.

\section{Dimanche 19 octobre}

9 h $00-9$ h 50 Eric BEDFORD : Dynamics of rational surface automorphisms of positive entropy.

10 h $00-10$ h 30 Henri De THÉLIN : Dynamics of meromorphic maps.

11 h 00 - 11 h 30 Mlle Léa BLANC-CEnTI : Stationary pseudoholomorphic discs.

11 h 40 - 12 h 30 Christer O. Kiselman : Prolongement analytique de solutions fondamentales des équations aux dérivées partielles. 